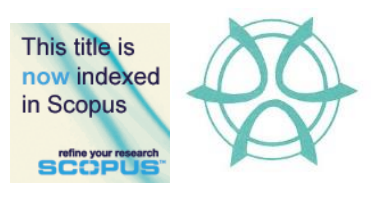

PLANNING MALAYSIA:

Journal of the Malaysian Institute of Planners

VOLUME 16 ISSUE 1 (2018), Page 245 - 255

\title{
IDENTIFYING THE LEVEL OF COMMUNITY INVOLVEMENT IN THE COMMUNITY ACTIVITIES AT KG. KUALA TELANG, KUALA LIPIS, PAHANG
}

\author{
Maheran Yaman ${ }^{1}$, Zainul Mukrim Baharuddin² \& Haza Hanurhaza Md \\ $\mathrm{Jani}^{3}$ \\ 1,2,3 Kulliyah of Architecture and Environmental Design, \\ INTERNATIONAL ISLAMIC UNIVERSITY MALAYSIA
}

\begin{abstract}
A community is a particular group of people that are bound by a similar cultural practice and activities. The continuation of the practising the local culture developed an identity for the community. Through time, the identity is strengthened by the level of community involvement in response to their participation in preserving the culture. The lack of community involvement would result to decreasing number of cultural practices. Eventually, the process contributed to a negative impact on the local identity. This paper addresses the importance of a community involvement concerning safeguarding the local culture and practices. Two objectives are outlined in achieving the aim. Firstly, to identify the list of the community activities. Secondly, to determine the level of community involvement at $\mathrm{Kg}$. Kuala Telang, Kuala Lipis. A quantitative method of analysis is adopted in the paper to achieve the objectives. The survey questionnaire is distributed to 58 respondents, and the result is analysed using descriptive statistics and Spearman correlation tests. The findings from the data collection are arranged into four categories, and the result is discussed accordingly as to answer the aim and objectives of the paper. As a final remark, the paper highlights the importance of community involvement and the methods to ensure the level of participation in response to community activities in the village.
\end{abstract}

Keyword: community involvement, village, culture, identity 
Maheran Yaman, Zainul Mukrim Baharuddin \& Haza Hanurhaza Md Jani

Identifying the Level of Community Involvement in The Community Activities at Kg. Kuala Telang, Kuala Lipis, Pahang

\section{INTRODUCTION}

Community involvement is defined by UNESCO as a process of developing a participation and cooperation of an individual in a particular community as a method to accomplish a specific activity (UNESCO. 2003). A community is bound by a specific cultural practice; the practice gradually shaped the identity of the local people (Bakar, Osman, \& Bachok, 2012a; Smith \& Akagawa, 2009). For that reason, community involvement holds an important role in strengthening the social structure and protecting the cultural identity of a community (Abdullah, 2011; Lewicka, 2008; Smith, 2006). In short, the level of community involvement contributed in building up the social activities of a community. The lack of community involvement would result in the degrading on the cultural and local identity of a particular community.

In regards to the statement, this paper is accentuated on identifying the level of community involvement at Kg. Kuala Telang, Kuala Lipis, Pahang. In general, the issues discovered in a village revolved around the method to protect and preserve a local culture as well as traditional practices. The lack of practising the traditional culture would cause the disappearing of a local identity for a particular community. For that reason, this paper aims to emphasise the importance of a community involvement in regards to safeguarding the local culture and practices. Two objectives are highlighted that are to identify the list of the community activities as well as to determine the level of community involvement in the village. The effort is perceived as an attempt to discover a technique in ensuring a perseverance of a community participation.

\section{LITERATURE REVIEW}

Community involvement is strongly related to the place attachment and sense of belonging to a specific area (Schmid, 2003; Bakar et al., 2012a; Moliner, Sales, \& Sanahuja, 2017; Omar, Omar, Othman, \& Yusoff, 2016). The level of attachment contributed to developing a willingness to participate with the community activities (Corcoran, 2002). For that reason, the understanding of the community origin, as well as history, helps in increasing the sense of attachment and belonging to the place (Firmansyah \& Fadlilah, 2016).

However, several studies have identified the contributing factors that led to the low level of community involvement. Among them are the lack of emphasis on the importance of individual participations (Bakar et al., 2012a; Bakar, Osman, \& Bachok, 2012b; Garnett, Cooper, Longhurst, Jude, \& Tyrrel, 2017), the deficiency in transmitting the knowledge on the local culture and tradition (Carli, 2001; Schmid, 2003), interference of contemporary over traditional practices (Abu Sadat, 2008; Bakar et al.,2012b; Beel et al., 2017; Omar et al., 2016), weak family institution, the need of practicing the tradition as well as the lack of interest and sense of attachment to the place (Whelan, Tellez, O"Brien, \& Fragoso, 2008; Frank, \& Lewis, 2004; Richwine, 2012; Tuan, 1977; Manzo \& Perkins, 2006; 
Omar et al., 2016). They are are observed as the factors that are causing the lack of community involvement. The causes are illustrated in Figure 1.

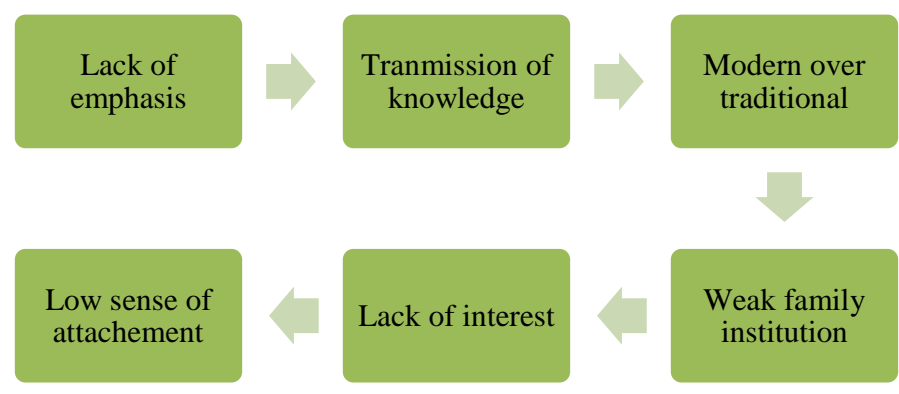

Figure 1: Causes to the lack of community involvement

There are several reasons to have caused the lack of community involvement. Therefore, the need to underline the importance of strengthening the community involvement are foreseen as necessary. Transmission of knowledge regarding the community activities is viewed as one of the steps to ensure the survival and continuity of community participation (Smeets, 2003; Smith \& Akagawa, 2009). The knowledge on the importance of maintaining the community involvement would develop the sense of appreciation, and it would eventually encourage the community to participate in the community activities actively.

\section{METHODOLOGY}

This paper is developed from a quantitative research. The survey questionnaire is intended to identify the level of community involvement at Kg. Kuala Telang, Kuala Lipis, Pahang. The questionnaire is structured into three main sections consisted of 18 questions. The first section is focusing on the respondent profile while the second sections are targeting to identify the types of community activities that are currently taking placed in the village as well as the respondents level of interest on each of the activities. A total of 24 activities are outlined with ten different lists on the level of interest. The result determines the list of community activities at the village and the level of its importance according to the local people. The final section consisted of 3 questions, and each of the questions is measured by a 5 point Likert scale ranging from strongly disagree to strongly agree.

A random sampling technique is adopted, and a total of 58 respondents are approached to answer the questionnaire. The data gathered is analysed using SPSS Statistics Software version 20. In order to determine the level of 
Maheran Yaman, Zainul Mukrim Baharuddin \& Haza Hanurhaza Md Jani

Identifying the Level of Community Involvement in The Community Activities at Kg. Kuala Telang, Kuala Lipis, Pahang

consistency in the structure of the questionnaire, a Cronbach's alpha is run. The value of the Cronbach's alpha for each section obtained 0.82 which indicate a good level of internal consistency.

\section{DATA ANALYSIS AND FINDINGS}

The result from the data collection is presented in four categories namely the demographic data, the level of community involvement, the premeasured step to increase community involvement, and suggestion to improve the community involvement in the village. The detail on the findings is elaborated in the following subsection.

\section{Demographic Data}

Based on the total 58 respondents, the analysis revealed 38 respondents are male while the remaining 20 are female. The age classification shows the population in the village ranges from young adult (ages 10-30years, pct. $=22.4 \%$ ), middleaged adults (ages 31-50years, pct. $=41.4 \%$ ), and older adults (age 51 and above, pct. $=36.2 \%$ ). The number of respondents originated from the village are classed into two categories, namely the local people $(86.2 \%)$ and non-local people $(13.8 \%)$. The percentage of the local people shows a potential for a high level of the sense of attachment towards the village. The years of residence is viewed as a method to evaluate respondent's level of attachment. The result is presented in Table 1.

Table 1: Years of residence

\begin{tabular}{llll}
\hline Level of Attachment & Years of Residence & F. & \% \\
\hline Low attachment & $:<15$ years & 7 & 12.1 \\
Middle attachment & $: 16-30$ years & 21 & 36.2 \\
High attachment & $: 31-45$ years & 13 & 22.4 \\
Very High attachment & $:>46$ years & 16 & 27.6 \\
\hline
\end{tabular}

Based on the result in Table 1, it is discovered that $50 \%$ of the total respondent demonstrated a high and very high level of attachment. Meanwhile, $36.2 \%$ had a middle level of attachment to the village. The result was interpreted as "the longer the respondent resides at the village, the higher their level of attachment." Therefore, the demographic data shows the middle to older adults has higher sentiment as well as personal attachment to the village.

\section{The Level of Community Involvement (CI) in the Village}

According to the result of the importance of the community activities, $98.3 \%$ of the respondent agreed that the activities are perceived as an important aspect that connecting the local people. Moreover, the activities are viewed as a benefit towards the local people as $100 \%$ of the respondent demonstrate a positive response towards the subject. Besides, the respondent highlighted there main 
PLANNING MALAYSIA

Journal of the Malaysia Institute of Planners (2018)

important people that played a significant role in influencing the involvement of the community. The highest contributor is the village development and security committee $(74.1 \%)$, followed by family members $(13.8 \%)$ and the third biggest contributor in influence the community involvement was neighbours (12.1\%). It is discovered that the village development and security committee hold the most significant influence in increasing community involvement in the village. The result is presented in Table 2 .

Table 2: Role in influencing the CI

\begin{tabular}{lll}
\hline Influence by & F. & \% \\
\hline Family Members & 8 & 13.8 \\
Neighbours & 7 & 12.1 \\
Village Development and Security Committee & 43 & 74.1 \\
District Council & 0 & 0.0 \\
State Government & 0 & 0.0 \\
\hline
\end{tabular}

In regards to the community involvement, there was a total of 24 activities conducted in the village. Based on the activities, the respondents were surveyed with their level of interest in participating in the activities. The result showed a great difference in the weightage of the community interest towards the activities (Figure 2).

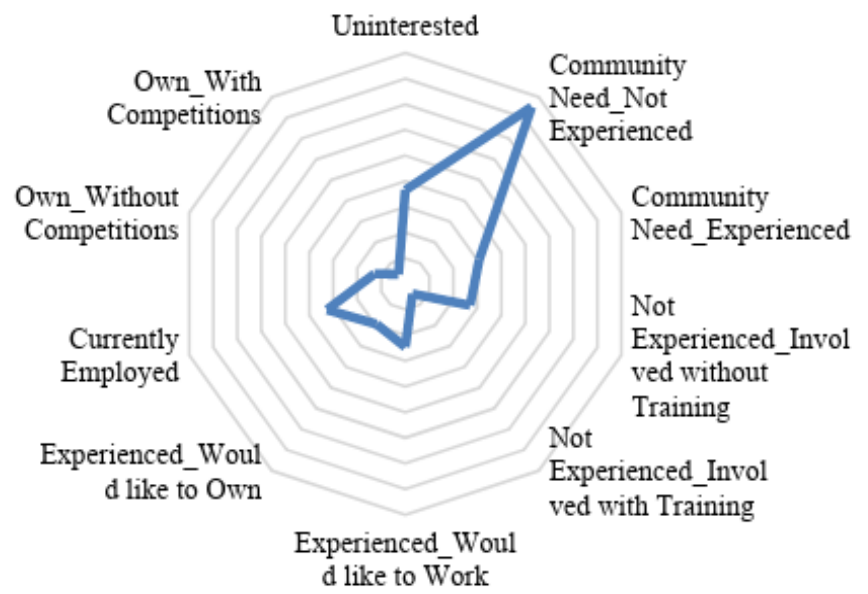

Figure 2: The weightage on the level of community interest

The majority of the respondents were interested in participating, and the activities were viewed as a need by the local people. Nevertheless, the local people had no experience in involving with the detail of the activities such as i) community nature sanctuary (44.83), ii) livestock products $(41.38 \%)$, iii) 
Maheran Yaman, Zainul Mukrim Baharuddin \& Haza Hanurhaza Md Jani

Identifying the Level of Community Involvement in The Community Activities at Kg. Kuala Telang, Kuala Lipis, Pahang

traditional performing arts as well as nature-based outdoor adventure (39.66\%) and iv) nature night tour as well as handicraft products (36.21\%). Among the 24 activities, the six activities mentioned above have obtained the four highest percentage in regards to the community need but lacking in term of experience. Therefore, the findings highlighted the list of the potential activities needed by the community that can be further developed or emphasised on.

Among the weightage of community interest, the result also showed the respondents were uninterested in participating in with activities. The lack of interest is interpreted as a threat towards community involvement in participating in the local activities. The study demonstrated the causes towards the lack of community involvement and interest. A correlation was conducted to identify the causes, and the result is presented in Table 3.

Table 3: Correlation on the causes

\begin{tabular}{lllllllll}
\hline Causes & $\mathbf{1}$ & $\mathbf{2}$ & $\mathbf{3}$ & $\mathbf{4}$ & $\mathbf{5}$ & $\mathbf{6}$ & $\mathbf{7}$ & $\mathbf{8}$ \\
\hline 1. Emphasis & 1 & & & & & & & \\
2. Interest & 0.65 & 1 & & & & & & \\
3. Guidance & 0.63 & 0.67 & 1 & & & & & \\
4. Support & 0.75 & 0.59 & 0.61 & 1 & & & & \\
5. Modern Life & 0.40 & 0.46 & 0.49 & 0.55 & 1 & & & \\
6. Appreciation & 0.67 & 0.68 & 0.67 & 0.74 & 0.68 & 1 & & \\
7. Socioeconomic & 0.55 & 0.60 & 0.47 & 0.61 & 0.43 & 0.71 & 1 & \\
8. Other culture & 0.51 & 0.48 & 0.51 & 0.55 & 0.50 & 0.68 & 0.59 & 1 \\
\hline ** Correlation is significant at the 0.01 level (2-tailed) & & & & & &
\end{tabular}

**Correlation is significant at the 0.01 level (2-tailed)

In general, there were eight causes of the lack of community involvement in participating in the community activities. Among them was the lack of emphasis, interest, guidance, support, appreciation, interference of modern lifestyle and other culture as well as imbalance socioeconomic. Based on Table 3 , with $99 \%$ confidence level, 11 variables with a strong correlation were discovered, and the result was presented as follows ( $\mathrm{p}$-value $<0.01$ ):

i. The lack of emphasis was strongly correlated with lack of interest $(r=0.65)$, support $(r=0.63)$, guidance $(r=0.75)$ and appreciation $(r=0.67)$.

ii. The lack of interest was strongly correlated with the lack of guidance $(r=0.67)$ and lack of appreciation $(\mathrm{r}=0.68)$.

iii. The lack of guidance was strongly correlated with the lack of appreciation $(\mathrm{r}=0.67)$.

iv. The lack of support was strongly correlated with lack of appreciation $(\mathrm{r}=0.74)$.

$v$. The interference of modern lifestyle was strongly correlated lack of appreciation $(\mathrm{r}=0.68)$.

vi. The lack of appreciation was strongly correlated with the imbalance socioeconomic $(r=0.71)$ and interference by other culture $(r=0.68)$. 
PLANNING MALAYSIA

Journal of the Malaysia Institute of Planners (2018)

The result highlights the list of the variable on the causes of the lack of community involvement, which had a strong correlation with other variables. As the causes were viewed as the reasons for lack of community involvement; therefore, there is a need to address a method to overcome the issues. Based on another correlation test on the needs of the community, a premeasured step in overcoming the lack of involvement is identified. The detail explanation is discussed in the following subsection.

\section{The Premeasured Step to Increase the Community Involvement in the Village}

Causes of the lack of community involvement have been identified, and therefore, a premeasured step to increase the level of participation is accentuated in the study. In general, the premeasured steps are targeted to underline the community needs as anticipated by the respondent. There are five strong correlations with 99\% confidence level identified in response to the method to increase local involvement in the village. The relationships are presented as follows ( $\mathrm{p}$-value $<0.01)$ :

i. Personal involvement was strongly correlated with the strength of the community activities $(r=0.60)$.

ii. The ability to transmit information between the community (local people) was strongly correlated with the confidence to transmit information to other people or tourist $(\mathrm{r}=0.79)$, and the practice would increase the number of tourists $(\mathrm{r}=$ $0.62)$.

iii. The effort to promote on cultural activities to the tourist was strongly correlated with the increasing number of tourist $(r=0.66)$.

iv. The need to generate and increase income was strongly correlated with the aspiration to participate in the community activity $(\mathrm{r}=0.62)$.

$v$. The confidence to voice out opinion was strongly correlated with the ability to generate personal income $(\mathrm{r}=0.64)$.

Based on the five relationships, it is revealed that the means to increase the local involvement include personal participation to strengthen the foundation of the community activities. Moreover, personal ability to deliver information about the community to other local people would develop confidence in transmitting the information to other people and eventually, this would increase the number of tourists. Furthermore, the effort to promote the activities would also contribute in inviting more tourists at the village. Other than that, personal participation in the community activities, as well as the confidence to express an individual opinion, showed a positive effect towards increasing or generating income. An individual participation opens an opportunity for them to voice out their opinion towards the possibility to enhance profits and financial stability in the village. 
Maheran Yaman, Zainul Mukrim Baharuddin \& Haza Hanurhaza Md Jani

Identifying the Level of Community Involvement in The Community Activities at Kg. Kuala Telang, Kuala Lipis, Pahang

The following subsection explains on the list of suggestion by the respondent on a method to improve the community involvement.

\section{Suggestions to Improve the Community Involvement in the Village}

This paper emphasises on the community involvement in Kg. Kuala Telang. It also highlights the causes of the lack of involvement as well as the premeasured steps to increase local participation. The respondent addresses suggestions to improve the current condition in the village. The suggestions are observed as a contribution to ensure the community activities in the village can be prolonged and practiced in the future.

In detail, the list of suggestions mentioned by the respondent is categorised into ten aspects. The aspects are underlined in response to the method anticipated to enhance the community involvement. The ten aspects are:

1. Awareness Campaign for Community Activities

2. Promote and Improve Community Activities

3. Encourage Younger Generation to Participate

4. Invite More Tourist

5. Active involvement by the Community, JKKK, ADUN, Government, and NGO

6. Opportunity to Voice Opinion

7. Generate Income and Budget

8. Encourage Social Works

9. Encourage Plant Cultivation

10. Promote Sport Activities

These are among the important suggestion highlighted by the respondent in regards to the community involvement in the village. The findings on the importance of the aspect are gathered through frequency count, and the result is presented in Figure 3. 


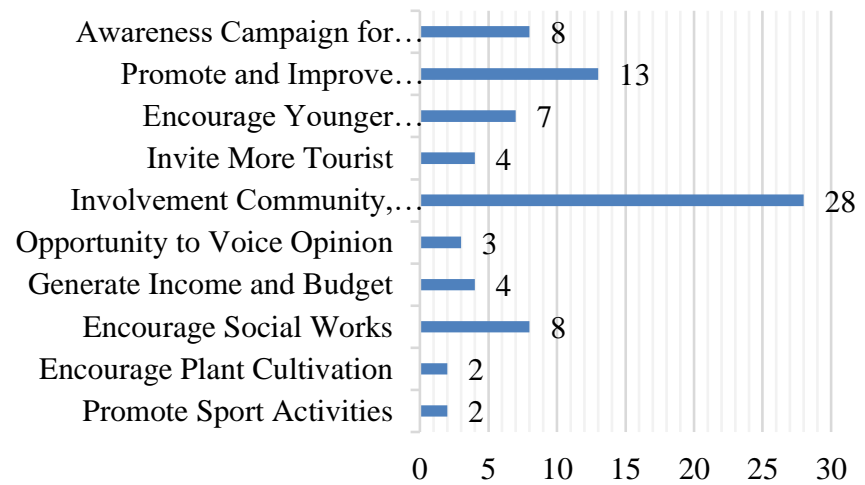

Figure 3: The list of suggestions addressed by respondents

According to Figure 3, the three main suggestions as mentioned by respondents are: i) to have an active involvement within the community, JKKK, ADUN, Government and NGO's (freq: 28 , pct: $48.28 \%$ ), ii) to promote and improve community activities (freq: 13 , pct: $22.41 \%$ ) and iii) to encourage social works (freq: 8 , pct: $13.80 \%$ ); and awareness campaign for community activities (freq: 8 , pct: $13.80 \%$ ).

The list of suggestions can be prioritised into ranking. The rank indicates the ranges for the importance of the aspect suggested by respondents. In short, the frequency count had identified seven raking to prioritise the list of suggestion. The detail on the result is presented in Table 4.

Table 4: Ranking on suggestions

\begin{tabular}{ll}
\hline Ranking & Suggestions \\
\hline One & Involvement Community, JKKK, ADUN, Government and NGO \\
Two & Promote and Improve Community Activities \\
Three & Encourage Social Works; and Awareness Campaign for Community \\
& Activities \\
Four & Encourage Younger Generation to Participate \\
Five & Generate Income and Budget; and Invite More Tourist \\
Six & Opportunity to Voice Opinion \\
Seven & Promote Sports Activities; and Encourage Plant Cultivation \\
\hline
\end{tabular}

The majority of the respondents highlights the importance of active involvement by the community as well as other relevant people. An active participation would assist in promoting and enhancing the community activities. Other than that, encouragement and awareness campaign is identified as a significant method to increase community involvement. 
Maheran Yaman, Zainul Mukrim Baharuddin \& Haza Hanurhaza Md Jani

Identifying the Level of Community Involvement in The Community Activities at Kg. Kuala Telang, Kuala Lipis, Pahang

\section{CONCLUSION}

The paper discusses the identifying the level of community involvement at $\mathrm{Kg}$. Kuala Telang Kuala Lipis. Through the assessment, it is discovered that the local people understand the importance of community involvement as significant ways to preserve the traditional cultural activities at their places. Nevertheless, the causes of the lack of participation are currently occurring, and the need to overcome as well as suggestions to improve the situation is highlighted in the paper as a method to address the problem. In addressing the importance of a community involvement, the respondent's underlined support and encouragement are the keys to ensure the participation of the local people. Besides, the community emphasises the need to provide a platform for them to learn and gain experience in continuing the community activities. The process is observed as a positive approach in encouraging local people to get involved in the community activities.

\section{ACKNOWLEDGEMENT}

This paper is part of a studio project for a second-year Landscape Architecture student in International Islamic University Malaysia (IIUM).

\section{REFERENCES}

Abdullah, M. (2011). Concept of equality in Islam. Available at www.islam.net Abu Sadat, N. (2008). Globalization as a challenge to Islamic cultural identity. The Journal of Interdisciplinary of Social Science, 2(6), 45-52.

Bakar, A. A., Osman, M. M., \& Bachok, S. (2012a). Community involvement in cultural activities: Theories and concept. $1^{\text {st }}$ Islamic Built Environment Conference: Proceedings of the IBECONF 2012. Universitas Islam Bandung, Bandung, Indonesia.

Bakar, A. A., Osman, M. M., \& Bachok, S. (2012b). Measuring community involvement in cultural activities: Case study of Malacca, Malaysia. National Conference of Postgraduate Research: Proceedings of the NCON-PGR 2012. Universiti Malaysia Pahang, Pekan, Pahang.

Beel, D. E., Wallace, C. D., Webster, G., Nguyen, H., Tait, E., Macleod, M., \& Mellish, C. (2017). Cultural resilience: The production of rural community heritage, digital archives and the role of volunteers. Journal of Rural Studies, 54, 459-468.

Carli, L. L. (2001). Gender social influence. Journal of Social, 57, 725-741.

Corcoran, M., P. (2002). Place attachment and community sentiment in marginalized neighborhoods: A European case study. Canadian Journal of Urban Research, 11, 201-221.

Firmansyah, F., \& Fadlilah, K. U. (2016). Improvement of involvement society in the context of smart community for cultural heritage preservation in Singosari. Procedia - Social and Behavioral Sciences, 227, 503-506. 
Frank, S. A., \& Lewis, G. B. (2004). Government employees working hard or hardly working? American Review of Public Administration, 4(1), 36-51

Garnett, K., Cooper, T., Longhurst, P., Jude, S., \& Tyrrel, S. (2017). A conceptual framework for negotiating public involvement in municipal waste management decision-making in the UK. Waste Management, 66, 210221.

Lewicka, M. (2008). Place attachment, place identity and place memory: Restoring the forgotten city past. Journal of Environmental Psychology, 28, 209-231.

Manzo, L. C., \& Perkins, D. D. (2006). Finding common ground: The importance of place attachment to community participation and planning. Journal of Planning Literature, 4, 20-335.

Moliner, O., Sales, A., \& Sanahuja, A. (2017). Social mapping in the context of a community-build day: Strategy to strengthen links with community in a small rural school. Procedia - Social and Behavioral Sciences, 237, 305-310.

Omar, D., Omar, K. A., Othman, S., \& Yusoff, Z. M. (2016). Youth participation in urban neighbourhood community. Procedia - Social and Behavioral Sciences, 234, 309-316.

Richwine, J. (2012, September 11). Government Employees Work Less than Private Sector Employees. Retrieved from https://www.heritage.org/jobs-and-labor/report/government-employeeswork-less-private-sector-employees

Schmid, H. (2003). Do women and men really live in different culture? Evidence from the BNC. Frankfurt: LMU Munchen

Smeets, R. (2003). Intangible cultural heritage and its link to tangible cultural and natural heritage. Available at www.jpf.go.jp.

Smith, L. (2006). Cultural heritage: Critical concepts in media and cultural studies. New York: Routledge.

Smith, L., \& Akagawa, N. (2009). Intangible Heritage. New York: Routledge.

Tuan, Y. (1977). Space and place: The perspective of experience Minneapolis. Minneapolis: University of Minnesota Press.

UNESCO (2003). Implementing the convention for the safeguarding of intangible cultural heritage. Available at www.unesco.org

Whelan, S., Tellez, L., O'Brien, M., \& Fragoso, M. (2008). Marriage and the public good: Ten principles. Available at www.winst.org. 